\title{
TRANSFER OF BASAL SLIDING VARIATIONS TO THE SURFACE OF A LINEARLY VISCOUS GLACIER
}

\author{
By Michael J. BAlise and Charles F. RAYMOND
}

(Geophysics Program, University of Washington, Seattle, Washington 98195, U.S.A.)

\begin{abstract}
The transfer of basal velocity anomalies to the surface of a glacier is investigated using a model of a planar parallel-sided slab (thickness $H$ ) of linear viscous rheology. Surface velocity parallel $\left(u_{\mathrm{s}}\right)$ and normal $\left(v_{\mathrm{s}}\right)$ to the surface is calculated for various spatial distributions of basal velocity anomalies with components parallel $\left(u_{\mathrm{b}}\right)$ and normal $\left(v_{\mathrm{b}}\right)$ to the surface. Four scales of differing behavior can be identified depending on the spatial length $L$ of the basal anomalies. At very short scales $(L \leqslant 1 H)$ there is essentially no response at the surface. At short scales $(1 H \leqslant$ $L \leqslant 5 H)$, a basal anomaly $u_{\mathrm{b}}$ induces a response in both $u_{\mathrm{s}}$ and $v_{\mathrm{s}}$. The spatial pattern of $u_{\mathrm{s}}$ is such that velocity peaks in $u_{\mathrm{s}}$ can be shifted from peaks in $u_{\mathrm{b}}$, and may differ in number. The amplitude of $u_{\mathrm{s}}$ is up to about $0.3\left|u_{\mathrm{b}}\right|$. The amplitude of the cross-component effect $v_{\mathrm{s}}$ may be greater than the amplitude of $u_{\mathrm{s}}$. A basal anomaly $v_{\mathrm{b}}$ induces a response in both $v_{\mathrm{s}}$ and $u_{\mathrm{s}}$. The pattern of $v_{\mathrm{s}}$ is the same as the pattern of $v_{\mathrm{b}}$, and the amplitude of $v_{\mathrm{s}}$ is up to about $0.7\left|v_{\mathrm{b}}\right|$. The amplitude of the cross-component effect $u_{\mathrm{s}}$ is less than the amplitude of $v_{\mathrm{s}}$. At intermediate scales $(5 H \leqslant L \leqslant 10 H)$, results differ from the short scale in two respects: velocity peaks in $u_{\mathrm{s}}$ correspond with peaks in $u_{\mathrm{b}}$; and surface amplitudes are increased, except for cross-component effects for which surface amplitudes are of the same order as at the short scale. These cross-component effects at the short and intermediate scales show in particular that substantial anomalous surface-normal motions can be induced by deformation, even though the basal velocity anomaly is parallel to the surface. At long scales $(10 H \leqslant L)$, the velocity anomaly at the surface is essentially the same as the anomaly at the bed. For all scales, the longitudinal strain-rate averaged over depth is larger in magnitude than the longitudinal strain-rate at the surface and, at the short scale, it may differ in sign, so that $v_{\mathrm{s}}$ cannot be easily estimated from surface strain-rate. Although the simplifications of the model do not allow its rigorous quantitative application to field measurements, the results indicate the need for caution in interpreting surface-velocity variations in terms of basal velocity anomalies. It is important to establish the spatial pattern of surface motions for any chance of a confident interpretation in terms of basal motions.
\end{abstract}

RÉsumé. Transmission en surface des fluctuations $d u$ glissement pour un glacier visqueux newtonien. On étudie, pour une plaque à faces parallèles d'épaisseur $H$ et de viscosité linéaire, l'effet en surface des fluctuations de la vitesse de dérapage. Les composantes de la vitesse superficielle parallèle $\left(u_{\mathrm{s}}\right)$ et perpendiculaire $\left(v_{\mathrm{s}}\right)$ à la surface sont calculées pour différentes distributions des anomalies de vitesses basales (composantes $u_{\mathrm{b}}$ et $v_{\mathrm{b}}$ ). Suivant la longueur $L$ des anomalies de vitesse basale on peut distinguer 4 échelles correpondant à des comportements différents. A très petite échelle $(L \leqslant H)$ il n'y a pas d'influence en surface. A petite échelle $(1 H \leqslant L \leqslant 5 H)$ une anomalie de $u_{\mathrm{b}}$ produit une anomalie à la fois sur $u_{\mathrm{s}}$ et sur $v_{\mathrm{s}}$. Les maxima de $u_{\mathrm{s}}$ peuvent être décalés par rapport à ceux de $u_{\mathrm{b}}$ et leur nombre peut être différent. L'amplitude de $u_{\mathrm{s}}$ peut atteindre $0,3\left|u_{\mathrm{b}}\right|$. L'amplitude de la composante perpendiculaire $v_{\mathrm{S}}$ peut être supérieure à celle de $u_{\mathrm{S}}$. Une anomalie $v_{\mathrm{b}}$ entraine également des variations de $u_{\mathrm{S}}$ et $v_{\mathrm{S}}$.
La distribution de $v_{\mathrm{s}}$ suit celle de $v_{\mathrm{b}}$ et l'amplitude de $v_{\mathrm{S}}$ atteint environ $0,7 \uparrow_{v_{\mathrm{b}}} \mid$. L'amplitude de la composante perpendiculaire $u_{\mathrm{S}}$ est inférieure à celle de $v_{\mathrm{s}}$. A une échelle intermédiaire $(5 H \leqslant L \leqslant 10 H)$ deux différences apparaissent par rapport à l'échelle précédente: les maxima de $u_{\mathrm{s}}$ correspondent aux maxima de $u_{\mathrm{b}}$ et les amplitudes sont plus importantes sauf pour la composante perpendiculaire où elles restent du même ordre de grandeur qu'à petite échelle. Ces effets sur la composante perpendiculaire à petite et moyenne échelle montrent que des anomalies dans la composante sub-verticale de la vitesse peuvent être provoquées par la déformation même si l'anomalie contre le lit n'affecte que la composante sub-horizontale. A grande échelle $(10 H \leqslant L)$ les anomalies superficielles sont pratiquement identiques aux anomalies contre le lit. A toutes les échelles la vitesse de déformation longitudinale moyenne sur l'épaisseur est supérieure à la vitesse de déformation en surface et, à petite échelle elle peut être de signe différent. Ainsi $v_{s}$ ne peut pas être facilement estimé à partir de la vitesse de déformation superficielle. Bien que la simplicité du modèle ne permette pas une comparaison quantitative rigoureuse avec les données de terrain, les résultats montrent que l'on doit être prudent lorsque l'on interprète des fluctuations superficielles de vitesse en termes de fluctuations de vitesse de glissement. Il est nécessaire de déterminer la structure spatiale des fluctuations de vitesses superficielies pour pouvoir raisonnablement les interpréter en termes de glissement.

ZUSAMMENFASSUNG. Übertragung von Schwankungen des Gleitens am Untergrund an die Oberfläche eines linear viskosen Gletschers. Die Übertragung von Schwankungen der Geschwindigkeit am Untergrund auf die Oberfläche eines Gletschers wird mit Hilfe eines Modells für eine ebene, parallel begrenzte Scheibe (Dicke $H$ ) mit linear viskoser Rheologie untersucht. Die Oberflächengeschwindigkeit parallel $\left(u_{\mathrm{S}}\right)$ und senkrecht $\left(v_{\mathrm{S}}\right)$ zur Oberfläche wird für verschiedene räumliche Verteilungen der Geschwindigkeitsschwankungen am Untergrund mit Komponenten parallel $\left(u_{\mathrm{b}}\right)$ und senkrecht $\left(v_{\mathrm{b}}\right)$ zur Oberfläche berechnet. Vier Grade verschiedenen Verhaltens kőnnen in Abhängigkeit von der räumlichen Lănge $L$ der Untergrundsanomalien festgestellt werden. Bei sehr kurzem Ausmass $(L \leqslant 1 H)$ tritt praktisch keine Reaktion an der Oberfläche ein. Bei geringem Ausmass $(1 H \leqslant L \leqslant 5 H)$ bewirkt eine Untergrundsanomalie $u_{\mathrm{b}}$ eine Reaktion sowohl in $u_{\mathrm{s}}$ wie in $v_{\mathrm{s}}$. Das răumliche Muster von $u_{\mathrm{s}}$ ist so gestaltet, dass Geschwindigkeitsspitzen in $u_{\mathrm{s}}$ verschoben erscheinen; ihre Zahl kann verschieden sein. Die Amplitude von $u_{\mathrm{s}}$ reicht bis etwa $0,3\left|u_{\mathrm{b}}\right|$. Die Amplitude des Effekts auf die Normalkomponente $v_{\mathrm{s}}$ kann grösser sein als die von $u_{\mathrm{s}}$. Eine Untergrundsanomalie $v_{\mathrm{b}}$ bewirkt eine Reaktion sowohl in $v_{\mathrm{s}}$ wie in $u_{\mathrm{s}}$. Das Muster von $v_{\mathrm{s}}$ ist dasselbe wie das von $v_{\mathrm{b}}$; die Amplitude von $v_{\mathrm{s}}$ erreicht etwa $0,7\left|v_{\mathrm{b}}\right|$. Die Amplitude des Effekts auf die Oberflächenkomponente $u_{\mathrm{s}}$ ist kleiner als die von $v_{\mathrm{s}}$. Bei mittleren Abmessungen $(5 H \leqslant L \leqslant 10 H)$ weichen die Ergebnisse in zweifacher Hinsicht von denen bei geringen Ausmassen ab: Geschwindigkeitsspitzen in $u_{\mathrm{s}}$ korrespondieren mit solchen in $u_{\mathrm{b}}$; die Amplituden an der Oberfläche sind verstärkt, ausser für die Effekte der Querkomponenten, 
für welche die Amplituden an der Oberfläche dieselbe Grössenordnung besitzen wie bei geringem Ausmass. Diese Effekte auf die Querkomponenten bei kurzen und mittleren Abmessungen zeigen vor allem, dass wesentliche anomale Bewegungen senkrecht zur Oberflăche durch Verformung erzeugt werden können, auch wenn die Geschwindigkeitsanomalie am Untergrund parallel zur Oberfläche verläuft. Bei grossem Ausmass $(10 H \leqslant L)$ ist die Geschwindigkeitsanomalie an der Oberfläche im wesentlichen gleich der am Untergrund. Für alle Masstäbe ist die Spannungsrate in Längsrichtung, gemittelt über die Eisdicke, grösser als die Lăngsspannungsrate an der Oberfläche; bei geringem

\section{INTRODUCTION}

The measurement of sliding velocities at the bases of glaciers or ice sheets is a fundamental observational problem. A method to determine these velocities is necessary for developing an understanding of the sliding process, and the testing of sliding laws for practical predictions of glacier speeds. Although the bases of glaciers can be reached by various means for direct observation of sliding speed and factors affecting it (e.g. Engelhardt and others, 1978; Vivian, 1980), these techniques are difficult and usually very expensive.

For this reason, it is natural to attempt to estimate sliding speed from measurements made at the surface. There are a number of cases involving various spatial and temporal scales where this has been attempted (e.g. Haefeli, 1970; Hodge, 1974; Bindschadler, 1983; paper in preparation by C.F. Raymond and W.D. Harrison). In fact, the most exciting recent discoveries and progress in understanding the sliding process have resulted from careful measurement of both the horizontal and vertical components of velocity at the glacier surface on a daily or shorter time-scale, by standard surveying and photogrammetric methods (Iken, 1977; Iken and others, 1983; paper in preparation by B. Kamb and H.F. Engelhardt). This kind of approach involves the estimation of velocity differences between the surface and the bed caused by ice deformation. In the case where the changes happen on a seasonal or longer time-scale, and glacier geometry and associated internal stresses obviously vary, changes in ice-deformation rate have been estimated from changes in depth and slope using results derived assuming deformation in simple shear parallel to the surface (Nye, 1952). In the case of very short time-scale variations for which glacier geometry is essentially constant, it has been assumed that the changes at the surface are nearly equal or at least proportional to those at the base. While these approaches give useful zero-order estimates of basal velocity variations, it is clear that there are errors arising from uncertainties about the ice rheology and changes in stress distribution.

The goal of this paper is to analyze effects coming from longitudinal interactions. These occur when temporal changes in sliding velocity vary longitudinally. The immediate motivation for this analysis was the mini-surge behavior of Variegated Glacier (Harrison and others, in press; Raymond and Malone, in press; paper in preparation by $B$. Kamb and H.F. Engelhardt). In these mini-surges the glacier did not speed up simultaneously at all locations. Instead, fast motion was confined to a rather narrow propagating zone, with high compression below it and extension above it. In reality, temporal changes in glacier speed, whether propagating or not, can be expected to show some localization and resulting longitudinal stress changes, which will tend to damp variations at the surface in comparison to the bed. The mathematical approach and simplifying assumptions used here are similar to ones used by Langdon and Raymond (1978), Hutter and others (1981), and Whillans and Johnsen (1983). However, in these earlier analyses interest was focused on the relationship between basal topography, surface topography, and internal motions. The relationship between basal and surface velocity was not examined systematically, which is the goal here.
Ausmass kann sie ein anderes Vorzeichen aufweisen, so dass $v_{S}$ aus der Spannungsrate an der Oberflăche nicht ohne weiteres abzuschătzen ist. Obwohl die Vereinfachungen des Modells dessen rigorose quantitative Anwendung auf Feldmessungen nicht zulassen, weisen die Ergebnisse darauf hin, dass bei der Deutung von Geschwindigkeitsschwankungen an der Oberfläche als Auswirkungen von Geschwindigkeitsschwankungen am Untergrund Vorsicht geboten ist. Es ist wichtig, das răumliche Muster von Oberflăchenbewegungen $\mathrm{zu}$ ermitteln, sofern man eine zuverlăssige Interpretation als Wirkung von Bewegungen am Untergrund gewinnen will.

\section{MATHEMATICAL DESCRIPTION OF PROBLEM}

\subsection{Definition of steady-state and anomalous motions}

The effect on glacier motion of changes in sliding velocity is most simply examined by separating the added anomalous motion $u(x, t)$ caused by a specific anomalous sliding-velocity distribution from a steady-state motion $\boldsymbol{u}_{0}(\boldsymbol{x})$ that would occur without the anomaly. The velocity anywhere in the glacier is then expressed as $u_{0}(x)+u(x, t)$.

The steady-state velocity distribution $u_{0}(x)$ and the corresponding stress distribution $\sigma_{0}(x)$ satisfy the field equations for flow under the action of gravity, with atmospheric pressure at the upper surface and the steady sliding $u_{0}\left(x_{b}\right)$ at the bed. The sum of the steady-state and anomalous distributions must also satisfy these field equations, with the boundary conditions changed to include the additional anomalous sliding velocity $u\left(x_{b}, t\right)$.

\subsection{Geometrical assumptions and coordinate system}

Planar slab geometry is assumed. Coordinates are chosen as shown in Figure 1, with the $x$-axis on the upper surface and positive down the slope, the $y$-axis normal to the

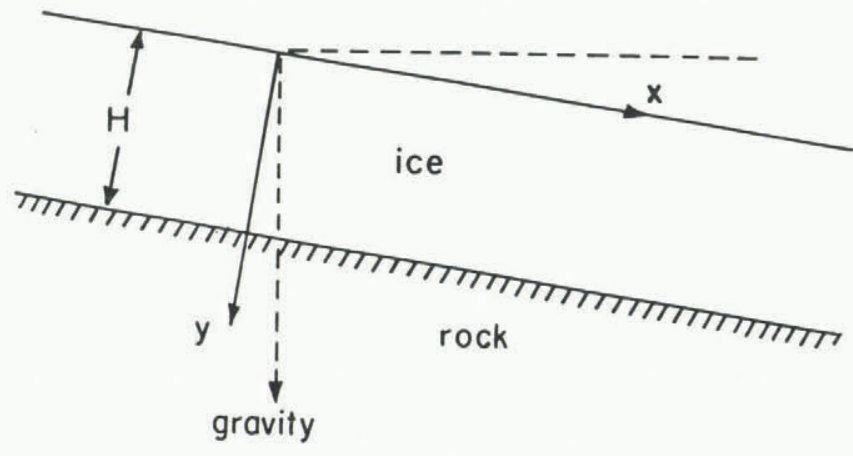

Fig. 1. Definition of geometrical quantities and coordinate system.

surface and positive towards the bed, and the $z$-axis horizontal across the slope. The steady-state velocity distribution $u_{0}(x)$ is assumed to be compatible with planar geometry and a constant ice thickness $H$, under a prescribed mass-balance distribution. The anomalous motion is assumed to be planar: the $x$ and $y$ components of velocity $u$ and $v$ may be non-zero functions of $x, y$, and $t$, but anomalous motion across the slope in the $z$ direction is everywhere zero.

This paper is concerned with the instantaneous velocity distribution at a specified time and for a specified planar geometry. A more complex and less well-defined problem would be the subsequent evolution of the geometry and velocity. Any basal velocity anomaly is likely to cause an anomalous normal velocity at the upper surface and gradually change the geometry of the glacier. This geometry change would feed back to affect the velocity distribution (Langdon and Raymond, 1978; Hutter, [ $\left.{ }^{c} 1983\right]$; Kamb and Echelmeyer, in press). If the time-scale of interest is short, or the velocity anomalies are small compared to the 
steady-state velocity $u_{0}$, then the geometry changes and corresponding velocity changes may be negligible. Under these restrictive conditions the problem of the eventual evolution of the surface geometry does not arise.

\subsection{Rheological assumptions and field equations}

The ice is assumed to flow as a Newtonian fluid of uniform dynamic viscosity $\eta$. The relevant field equations are the equation of continuity for incompressible flow, and the Navier-Stokes equations. Velocity anomalies are assumed to vary slowly enough that acceleration terms are negligible. From the assumptions that the motion is planar and that the steady-state distributions $\boldsymbol{u}_{0}$ and $\sigma_{0}$ satisfy the equations with body force from gravity, standard considerations yield the following field equations for the velocity-anomaly components $u$ and $v$, and the anomalous pressure $p$ :

$$
\begin{gathered}
\frac{\partial u}{\partial x}+\frac{\partial v}{\partial y}=0, \\
\eta\left[\frac{\partial^{2} u}{\partial x^{2}}+\frac{\partial^{2} u}{\partial y^{2}}\right]-\frac{\partial p}{\partial x}=0, \\
\eta\left[\frac{\partial^{2} v}{\partial x^{2}}+\frac{\partial^{2} v}{\partial y^{2}}\right]-\frac{\partial p}{\partial y}=0 .
\end{gathered}
$$

The gravity body force does not appear in these equations because the steady-state stress distribution $\sigma_{0}$ is in static equilibrium with gravity, and the linearity of the equations results in the anomaly fields being independent of and additional to the steady-state distribution.

\subsection{Boundary conditions}

The boundary conditions to be applied are atmospheric pressure on the upper surface and a prescribed velocity at the base. At the upper surface the steady-state distributions $u_{0}$ and $\sigma_{0}$ correspond to atmospheric pressure. The additional stress on this surface from the anomaly distributions $u$ and $\sigma$ must therefore be zero. For the given coordinate system this is expressed as

$$
\begin{aligned}
& \sigma_{y y}(x, 0, t)=\left.\left[2 \eta \frac{\partial v}{\partial y}-p\right]\right|_{y=0}=0, \\
& \sigma_{x y}(x, 0, t)=\left.\eta\left[\frac{\partial u}{\partial y}+\frac{\partial v}{\partial x}\right]\right|_{y=0}=0,
\end{aligned}
$$

keeping in mind the restrictions on the geometry of the upper surface discussed in the previous section. At the base, a prescribed velocity anomaly is expressed as

$$
\begin{aligned}
& u(x, H, t)=u_{\mathrm{b}}(x, t), \\
& v(x, H, t)=v_{\mathrm{b}}(x, t) .
\end{aligned}
$$

Equation (5a) is appropriate to slip along a flat base, and Equation (5b) allows for a simple approximation of the opening and closing of cavities.

A physically based sliding law relating basal velocity to basal stress, with spatially or temporally varying parameters, could also be used instead of Equation (5a). From a physical point of view, this would be a more direct approach to the origin of the basal velocity anomalies. From an observational point of view, it is better to relate surface velocity directly to basal velocity, especially since in practice a realistic sliding law is not known. The mathematical formulations for these two approaches are somewhat different. However, except possibly for cases involving mathematical singularities, the results of one formulation could be interpreted in terms of the other.

\subsection{Solution technique}

Equations (1) to (3) are solved using a stream function $\Psi$ such that

$$
u=\frac{\partial \psi}{\partial y} \quad v=-\frac{\partial \psi}{\partial x} .
$$

Equation (1) is trivially satisfied for any choice of $\psi$. Substitution of Equation (6) into Equations (2) and (3) gives two corresponding equations for $\boldsymbol{\psi}$ and $p$. Differentiation of Equation (2) with respect to $y$ and Equation (3) with respect to $x$ and the requirement $\partial^{2} p / \partial x \partial y=\partial^{2} p / \partial y \partial x \mathrm{im}-$ plies that $\psi$ must be biharmonic, that is

$$
\frac{\partial^{4} \Psi}{\partial x^{4}}+2 \frac{\partial^{4} \Psi}{\partial x^{2} \partial y^{2}}+\frac{\partial^{4} \Psi}{\partial y^{4}}=0
$$

Furthermore, when $\psi$ is biharmonic, $p$ can always be found from a path-independent integration of Equations (2) and (3). Thus the solution of Equations (1) to (3) is reduced to the solution of Equation (7)

To solve Equation (7), the boundary conditions in Equations (4) and (5) must be expressed in terms of $\psi$. Treatment of Equation (4a) is simplified if it is equivalently expressed as $\partial \sigma_{y y}(x, 0, t) / \partial x=0$, plus the requirement that at some point on $y=0, g_{y}=0 \quad$ (e.g. $\sigma_{y y}(0,0, t)=0$ ). In this differentiated form of Equation (4a), $\partial p / \partial x$ and $\partial^{2} v / \partial x \partial y$ can be calculated in terms of $\Psi$ from Equations (2) and (6) to find

$$
\left.\rightarrow\left[3 \frac{\partial^{3} \psi}{\partial x^{2} \partial y}+\frac{\partial^{3} \psi}{\partial y^{3}}\right]\right|_{y=0}=0
$$

Substitution of Equation (6) into Equations (4b), (5a), and (5b) gives

$$
\begin{gathered}
\left.\eta\left(\frac{\partial^{2} \Psi}{\partial y^{2}}-\frac{\partial^{2} \Psi}{\partial x^{2}}\right]\right|_{y=0}=0, \\
\left.\frac{\partial \Psi}{\partial y}\right|_{y=H}=u_{\mathrm{b}}(x, t), \\
-\left.\frac{\partial \Psi}{\partial x}\right|_{y=H}=v_{\mathrm{b}}(x, t) .
\end{gathered}
$$

\subsection{Some properties of solutions}

Because of the linearity of Equations (1) to (3) or equivalently Equation (7), it is apparent that if $\psi^{(a)}$ and $\psi^{(b)}$ are solutions, then $\psi=\psi^{(a)}+\psi^{(b)}$ is also a solution. Furthermore, if $\psi^{(a)}$ and $\psi^{(b)}$ satisfy the boundary conditions in Equations (8) and (9) corresponding to $u_{b}(a)$ and $u_{\mathrm{b}}(b)$ in Equation (9a) and $v_{\mathrm{b}}(a)$ and $v_{\mathrm{b}}(b)$ in Equation (9b), then $\Psi$ also satisfies the boundary conditions with $u_{\mathrm{b}}$ $=u_{\mathrm{b}}(a)+u_{\mathrm{b}}(b)$ and $v_{\mathrm{b}}=v_{\mathrm{b}}(a)+v_{\mathrm{b}}(b)$. This expresses the well-known principle of superposition of solutions. It is also evident that if $v_{\mathrm{b}}=0$, so that $\psi$ is a solution corresponding to a basal velocity $u_{\mathrm{b}}$, then $\partial \psi / \partial x$ is also a solution and corresponds to a basal velocity $\partial u_{\mathrm{b}} / \partial x$. These properties can be used to generate new solutions from existing ones.

Another important property of the equations is that they depend on time only through boundary conditions in Equations (9a) and (9b). This arises because of the assumed fluid rheology and the absence of acceleration terms, so that the internal flow responds to the basal boundary condition without time lag. An important consequence of this is illustrated by the following example. Suppose $v_{\mathrm{b}}=0$, so that $\psi(x, y)$ is a solution corresponding to $u_{\mathrm{b}}(x)$, then $a(t) \psi(x$ - $w t, y)$ is a solution corresponding to $a(t) u_{\mathrm{b}}(x-w t)$. Thus a solution for a certain time-independent, fixed spatial distribution can easily be modified to give a time-varying amplitude, or a propagating solution of the same wave shape. The solutions in the following sections will only be written in time-independent form, with the understanding that the corresponding propagating solutions can easily be determined.

Finally, it is noteworthy that the dynamic viscosity $n$ drops out of all of the Equations (7) through (9b) which determine $\psi$. This arises because there are no prescribed 
stress-boundary conditions other than the free upper surface, and no body force. In consequence, the anomalous velocity is independent of $\boldsymbol{\eta}$ and differences in the velocity distribution arise only from differences in the kinematic boundary conditions in Equations (9a) and ( $9 \mathrm{~b})$. However, the anomalous stress distribution will depend on $\eta$, although this distribution is not examined explicitly in this paper.

\section{SOLUTION METHODS}

3.1. Harmonic surface-parallel basal velocity anomaly Suppose the velocity anomaly at the base of the glacier is

$$
\begin{gathered}
u_{\mathrm{b}}(x)=U_{\mathrm{b}} \sin k x, \\
v_{\mathrm{b}}(x)=0
\end{gathered}
$$

where $U_{\mathrm{b}}$ is the amplitude of the basal anomaly. With the given rheology and assumptions, the velocity throughout the ice mass will also vary harmonically. A solution to Equation (7) varying harmonically with $x$ is

$$
\begin{gathered}
\Psi=U_{\mathrm{b}}\left[\frac{A_{u^{(k)}}}{k} \mathrm{e}^{k y}+\frac{B_{u}(k)}{k} \mathrm{e}^{-k y}+C_{u}(k) y \mathrm{e}^{k y}\right. \\
\left.+D_{u}(k) y \mathrm{e}^{-k y}\right] \sin k x .
\end{gathered}
$$

Boundary conditions in Equations (8) and (9) give four equations which determine the coefficients $A_{u}, B_{u}, C_{u}$, and $D_{u}$ as follows

$$
\begin{gathered}
A_{u}=B_{u}=-k H \frac{\mathrm{e}^{k H}+\mathrm{e}^{-k H}}{2+4 k^{2} H^{2}+\mathrm{e}^{2 k H}+\mathrm{e}^{-2 k H}}, \\
C_{u}=\frac{\mathrm{e}^{k H}+(1+2 k H) \mathrm{e}^{-k H}}{2+4 k^{2} H^{2}+\mathrm{e}^{2 k H}+\mathrm{e}^{-2 k H}}, \\
D_{u}=\frac{(1-2 k H) \mathrm{e}^{\mathrm{kH}}+\mathrm{e}^{-k H}}{2+4 k^{2} H^{2}+\mathrm{e}^{2 k H}+\mathrm{e}^{-2 k H}} .
\end{gathered}
$$

The velocity anomaly at any point $(x, y)$ can be found from Equations (6), (11), and (12). The surface-parallel component at $(x, y)$ is

$$
\begin{array}{r}
u(x, y)=\frac{\partial \psi(x, y)}{\partial y} \\
=U_{\mathrm{b}}\left[A_{u} \mathrm{e}^{k y}-B_{u} \mathrm{e}^{-k y}+\left(C_{u}+C_{u} k y\right) \mathrm{e}^{k y}\right. \\
=T_{u u}(k, y) u_{\mathrm{b}}(x) \\
\left.+\left(D_{u}-D_{u} k y\right) \mathrm{e}^{-k y}\right] \sin k x
\end{array}
$$

and the surface-normal component is

$$
\begin{aligned}
& v(x, y)=-\frac{\partial \psi(x, y)}{\partial x}, \\
& =-U_{\mathrm{b}}\left[A_{u} \mathrm{e}^{k y}+B_{u} \mathrm{e}^{-k y}+C_{u} k y \mathrm{e}^{k y}+D_{u} k y \mathrm{e}^{-k y}\right] \cos k x \\
& =T_{u \nu}(k, y) u_{\mathrm{b}}\left[x+\frac{\pi}{2 k}\right]
\end{aligned}
$$

Here

$$
\begin{gathered}
T_{u u}(k, y) \equiv A_{u} \mathrm{e}^{k y}-B_{u} \mathrm{e}^{-k y}+\left(C_{u}+C_{u} k y\right) \mathrm{e}^{k y} \\
+\left(D_{u}-D_{u} k y\right) \mathrm{e}^{-k y}
\end{gathered}
$$

and

$$
T_{u \nu}(k, y) \equiv-A_{u} \mathrm{e}^{k y}-B_{u} \mathrm{e}^{-k y}-C_{u} k y \mathrm{e}^{k y}-D_{u} k y \mathrm{e}^{-k y} .
$$

The velocities consist of a transfer or filter function multiplying the basal velocity $u_{\mathrm{b}}$. The surface-parallel velocity component anywhere in the glacier is in phase with the surface-parallel velocity at the base; the surface-normal velocity component is everywhere $90^{\circ}$ out of phase from the surface-parallel velocity component.

The velocity-transfer functions evaluated at the surface $(y=0)$ are

$\left.T_{u u s}(k) \equiv T_{u u}(k, y)\right|_{y=0}=\frac{(2-2 k H) \mathrm{e}^{k H}+(2+2 k H) \mathrm{e}^{-k H}}{2+4 k^{2} H^{2}+\mathrm{e}^{2 k H}+\mathrm{e}^{-2 k H}}$

for the surface-parallel velocity component, and

$$
\left.T_{u v s}(k) \equiv T_{u v}(k, y)\right|_{y=0}=\frac{2 k H \mathrm{e}^{k H}+2 k H \mathrm{e}^{-k H}}{2+4 k^{2} H^{2}+\mathrm{e}^{2 k H}+\mathrm{e}^{-2 k H}}
$$

for the surface-normal component.

Schematics of the internal motion for harmonic surfaceparallel basal velocity anomalies of a short and a long nondimensional wavelength $\lambda / H$ are shown in Figure $2 a$ and $b$. The important difference between these two cases is that for the short wavelength the velocity anomaly recirculates, while for long wavelengths it does not. This leads to interesting effects at the surface; particularly for short wavelengths the surface-parallel component will have an opposite direction at the surface to that at the base. (This can either be viewed as a sign change or a $180^{\circ}$ phase shift.) Also, at a certain intermediate wavelength $\lambda / H \approx 5.2$, the amplitude at the surface of the surface-parallel velocity component is zero. At this wavelength the surface amplitude of the surface-normal component reaches its maximum. These effects are summarized in Figure 3.

\subsection{Harmonic surface-normal basal velocity anomaly}

Now suppose that the velocity anomaly at the base of the glacier is

$$
\begin{aligned}
& u_{\mathrm{b}}(x)=0, \\
& v_{\mathrm{b}}(x)=V_{\mathrm{b}} \cos k x
\end{aligned}
$$

where $V_{\mathrm{b}}$ is the amplitude of the basal anomaly. A solution to Equation (7) then is

$$
\begin{aligned}
\Psi=V_{\mathrm{b}}\left[\frac{A_{v}(k)}{k}\right. & \mathrm{e}^{k y}+\frac{B_{v}(k)}{k} \mathrm{e}^{-k y} \\
& \left.+C_{v}(k) y \mathrm{e}^{k y}+D_{\nu}(k) y \mathrm{e}^{-k y}\right] \sin k x .
\end{aligned}
$$

Using boundary conditions in Equations (8) and (9), the coefficients $A_{v}, B_{v}, C_{v}$, and $C_{v}$ are found to be

$$
\begin{aligned}
& A_{v}=B_{v}=-\frac{(1+k H) \mathrm{e}^{k H}+(1-k H) \mathrm{e}^{-k H}}{2+4 k^{2} H^{2}+\mathrm{e}^{2 k H}+\mathrm{e}^{-2 k H}}, \\
& C_{v}=\frac{\mathrm{e}^{k H}+(1-2 k H) \mathrm{e}^{-k H}}{2+4 k^{2} H^{2}+\mathrm{e}^{2 k H}+\mathrm{e}^{-2 k H}}, \\
& D_{v}=-\frac{(1+2 k H) \mathrm{e}^{k H}+\mathrm{e}^{-k H}}{2+4 k^{2} H^{2}+\mathrm{e}^{2 k H}+\mathrm{e}^{-2 k H}} .
\end{aligned}
$$



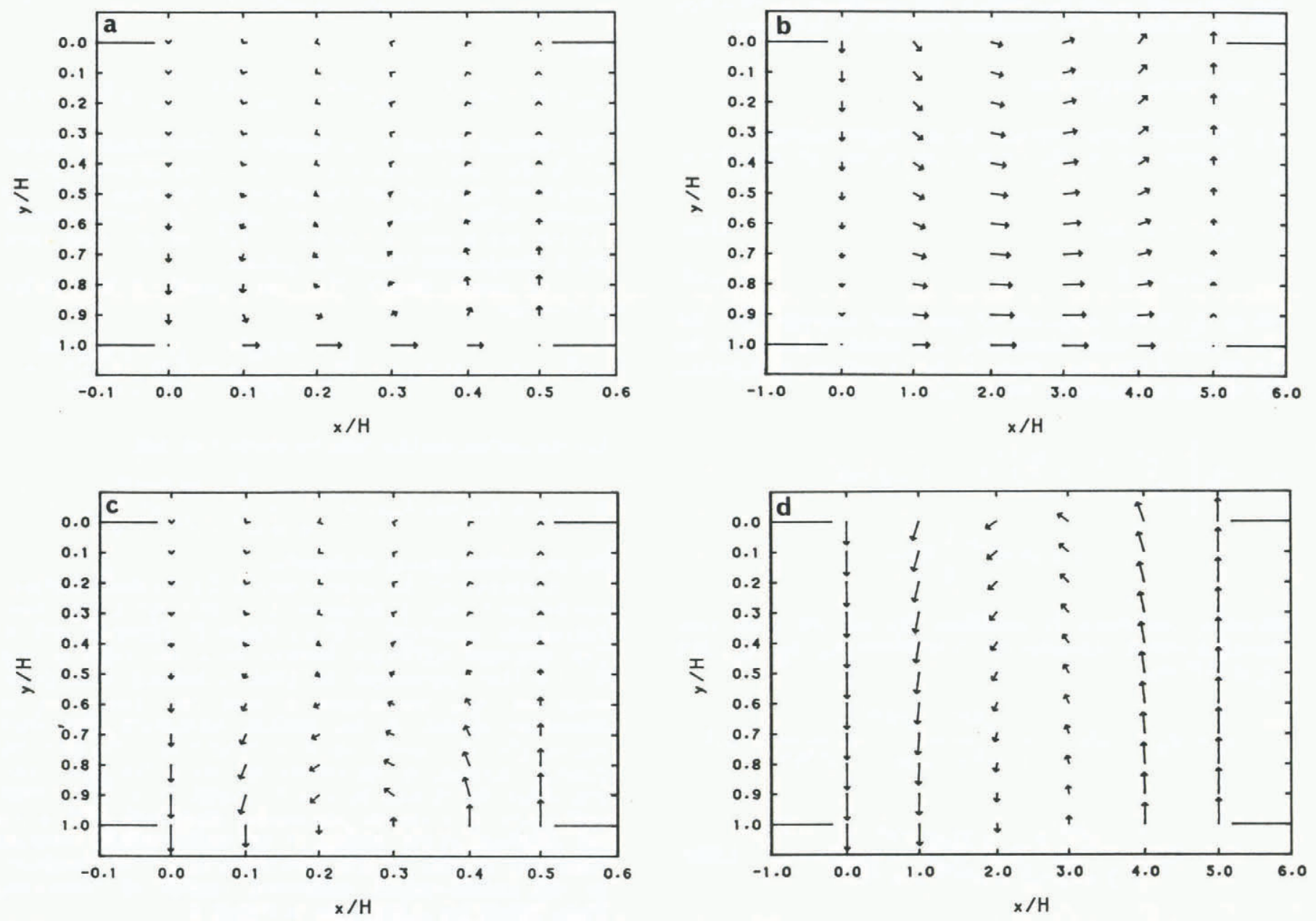

Fig. 2. Contrasting patterns of motion represented schematically for harmonic basal velocity anomalies (shown for $a$ half wavelength): (a) basal anomaly $u_{b}$, short wavelength $(\lambda / H=1) ;(b)$ basal anomaly $u_{b}$, long wavelength $(\lambda / H=10)$; (c) basal anomaly $v_{b}$, short wavelength $(\lambda / H=1)$; and (d) basal anomaly $v_{b}$, long wavelength $(\lambda / H=10)$.

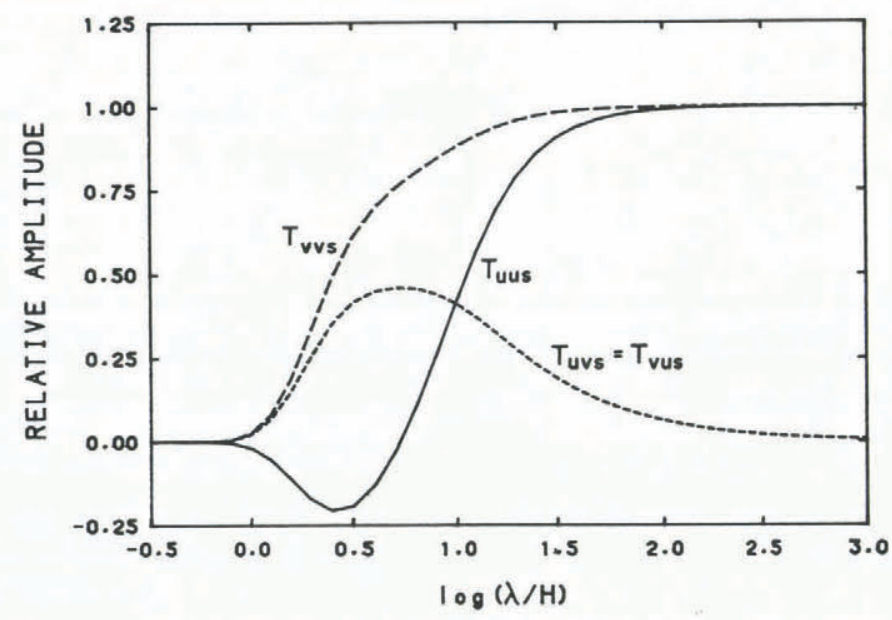

Fig. 3. Relative amplitudes of surface velocity, caused by harmonic variation in basal velocity (of unit amplitude). Solid line, $T_{u u s} ;$ dashed line, $T_{v v s} ;$ short dashed line, $T_{\text {uvs }}=T_{\text {vus }}$. 
The resulting velocity anomaly at a point $(x, y)$ is

$$
\begin{aligned}
u(x, y) & =\frac{\partial \Psi(x, y)}{\partial y} \\
& =V_{\mathrm{b}}\left[A_{\nu} \mathrm{e}^{k y}-B_{v} \mathrm{e}^{-k y}+\left(C_{\nu}+C_{v} k y\right) \mathrm{e}^{k y}+\left(D_{v}-D_{v} k y\right) \mathrm{e}^{-k y}\right] \sin k x \\
& =V_{\mathrm{b}}\left[-A_{v} \mathrm{e}^{k y}+B_{v} \mathrm{e}^{-k y}-\left(C_{v}+C_{v} k y\right) \mathrm{e}^{k y}-\left(D_{v}-D_{v} k y\right) \mathrm{e}^{-k y}\right][-\sin k x] \\
& =T_{v u}(k, y) \nu_{\mathrm{b}}\left[x+\frac{\pi}{2 k}\right]
\end{aligned}
$$

and

$$
\begin{aligned}
v(x, y) & =-\frac{\partial \psi(x, y)}{\partial x} \\
& =-V_{\mathrm{b}}\left[A_{v} \mathrm{e}^{k y}+B_{v} \mathrm{e}^{-k y}+C_{\nu} k y \mathrm{e}^{k y}+D_{v} k y \mathrm{e}^{-k y}\right] \cos k x \\
& =T_{v v}(k, y) v_{\mathrm{b}}(x)
\end{aligned}
$$

where

$$
T_{v u}(k, y) \equiv-A_{\nu} \mathrm{e}^{k y}+B_{\nu} \mathrm{e}^{-k y}-\left(C_{\nu}+C_{\nu} k y\right) \mathrm{e}^{k y}-\left(D_{\nu}-D_{\nu} k y\right) \mathrm{e}^{-k y},
$$

and

$$
T_{v v}(\mathrm{k}, \mathrm{y}) \equiv-A_{v} \mathrm{e}^{k y}-B_{v} \mathrm{e}^{-k y}-C_{v} k y \mathrm{e}^{k y}-D_{v} k y \mathrm{e}^{-k y} .
$$

The velocity-transfer functions evaluated at the surface $(y=0)$ are

$$
\left.T_{v u s}(k) \equiv T_{v u}(k, y)\right|_{y=0}=\frac{2 k H \mathrm{e}^{k H}+2 k H \mathrm{e}^{-k H}}{2+4 k^{2} H^{2}+\mathrm{e}^{2 k H}+\mathrm{e}^{-2 k H}}
$$

for the surface-parallel velocity component, and

$$
\left.T_{v v s}(k) \equiv T_{v v}(k, y)\right|_{y=0}=\frac{(2+2 k H) \mathrm{e}^{k H}+(2-2 k H) \mathrm{e}^{-k H}}{2+4 k^{2} H^{2}+\mathrm{e}^{2 k H}+\mathrm{e}^{-2 k H}}
$$

for the surface-normal component.

Comparison of Equation (21a) with Equation (15b) shows that $T_{v u s}=T_{u v s}$, i.e. the "cross-component" transfer functions are equal at the surface.

Schematics of the flow for harmonic basal surfacenormal anomalies of a short and a long non-dimensional wavelength are shown in Figure $2 \mathrm{c}$ and $d$. The major difference is that the amplitude of the surface velocity is greater for the longer-wavelength anomaly. The amplitudes at the surface of the surface-parallel and surface-normal components also vary relative to each other depending on the wavelength, although not in a significant manner for the schematics shown. These effects are summarized in Figure 3.

\subsection{Fourier transform solution}

The Fourier-transform method theoretically allows surface solutions to be found for any pattern of basal velocity $u_{\mathrm{b}}$ and $v_{\mathrm{b}}$. The Fourier transform and the inverse transform are defined as

$$
\begin{aligned}
& \hat{\mathrm{f}}(k) \equiv \int_{-\infty}^{\infty} \mathrm{f}(x) \mathrm{e}^{-i k x} \mathrm{~d} x, \\
& \mathrm{f}(x) \equiv \frac{1}{2 \pi} \int_{-\infty}^{\infty} \hat{\mathrm{f}}(k) \mathrm{e}^{i k x} \mathrm{~d} k .
\end{aligned}
$$

Using Equation (22a), the transform of Equation (7) is

$$
k^{4} \hat{\psi}-2 k^{2} \frac{\partial^{2} \hat{\psi}}{\partial y^{2}}+\frac{\partial^{4} \hat{\psi}}{\partial y^{4}}=0 .
$$

A solution for $\hat{\boldsymbol{\psi}}$ is

$\hat{\Psi}=\frac{A(k)}{k} \mathrm{e}^{k y}+\frac{B(k)}{k} \mathrm{e}^{-k y}+C(k) y \mathrm{e}^{k y}+D(k) y \mathrm{e}^{-k y}$.

By transforming the boundary conditions (Equations (8) and (9)), the coefficients $A, B, C$, and $D$ are found, and are most simply written in terms of the coefficients in Equations (12) and (18):

$$
\begin{aligned}
A=B & =A \hat{u}_{\mathrm{u}}-i A_{v} \hat{v}_{\mathrm{b}}, \\
C & =C_{u} \hat{u}_{\mathrm{b}}-i C_{v} \hat{v}_{\mathrm{v}}, \\
D & =D_{u} \hat{u}_{\mathrm{b}}-i D_{v} \hat{v}_{\mathrm{v}} \mathrm{b}
\end{aligned}
$$

Here $\hat{u}_{\mathrm{b}}(k)$ is the Fourier transform of the surface-parallel component of the basal velocity anomaly, and $\hat{v}_{\mathrm{b}}(k)$ is the transform of the surface-normal component of the basal velocity anomaly. These equations are analogous to those found for a single harmonic component in sections 3.1 and 3.2 . 
The actual basal anomaly components $u_{\mathrm{b}}(x)$ and $v_{\mathrm{b}}(x)$ must be specified (as two of the boundary conditions). From the transformed basal velocity components $\hat{u}_{\mathrm{b}}$ and $\hat{v}_{\mathrm{b}}$ the transformed stream function $\hat{\boldsymbol{\psi}}$ is determined using Equations (24) and (25). This is used to calculate the transformed velocities anywhere in the glacier:

$$
\begin{aligned}
& \hat{u}(k, y)=\frac{\partial \hat{\psi}(k, y)}{\partial y}, \\
& \hat{v}(k, y)=-i k \hat{\psi}(k, y) .
\end{aligned}
$$

If these are written out in terms of the individual coefficients (Equations (25)), then the transformed velocities can easily be rewritten in terms of the transfer functions (Equations (14) and (20)). Then, when evaluated at the surface, the transformed velocity components are:

$$
\begin{aligned}
& \hat{u}_{\mathrm{s}}=T_{u u s} \hat{u}_{\mathrm{b}}+i T_{u v s} \hat{v}_{\mathrm{b}}, \\
& \hat{v}_{\mathrm{s}}=T_{v v s} \hat{v}_{\mathrm{b}}+i T_{u v s} \hat{u}_{\mathrm{b}} .
\end{aligned}
$$

These surface-transfer functions are given explicitly in Equations (15) and (21), $T_{u v s}$ is used instead of $T_{v u s}$ in Equation (27a), since these two transfer functions are identical.

The Fourier-transform solutions in the following sections were calculated using a discrete Fourier-transform routine. The discrete Fourier transform assumes that the function is periodic. The surface effects of this assumption can be minimized by having a length of at least $2.5 \mathrm{H}$ on each side of the region of interest in the basal function (since this is about the maximum distance to which surface effects spread out from the basal function).

\section{SOLUTIONS FOR BASAL VELOCITY FRONTS AND PEAKS}

\subsection{Surface response to basal front}

An anomaly in the surface-parallel component of basal velocity that has the form of a front of amplitude (half-height) $U_{\mathrm{b}}$ can be expressed as:

$$
u_{\mathrm{b}}(x)= \begin{cases}U_{\mathrm{b}} & x<0, \\ -U_{\mathrm{b}} & x>0,\end{cases}
$$

$$
v_{\mathrm{b}}(x)=0 .
$$

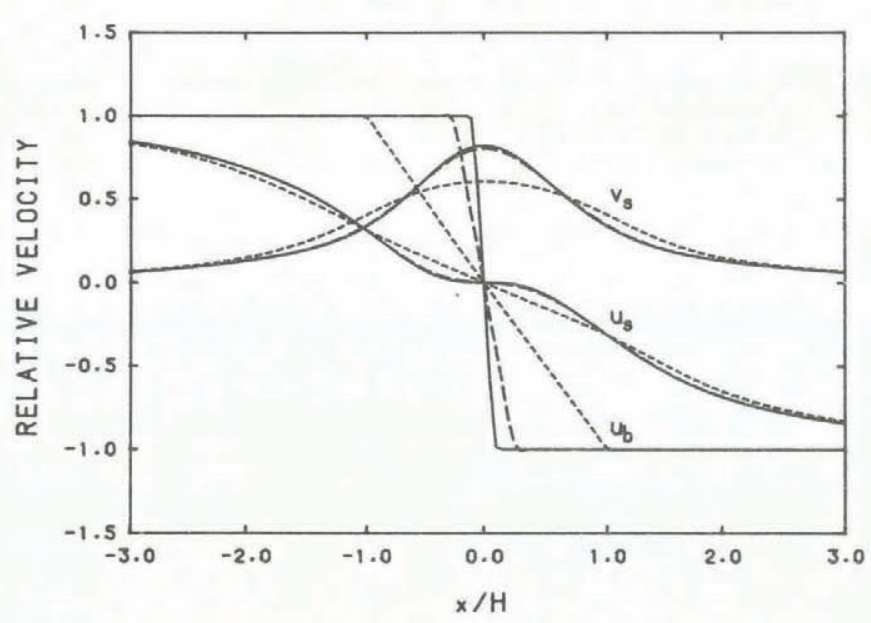

Fig. 4. Basal and surface velocities for a basal velocity anomaly $u_{b}$ : a sharp front shown by solid lines, a steep ramp wave $(r=0.025)$ shown by dashed lines where distinguishable, and a less steep ramp wave $(r=0.1)$ shown by short dashed lines. Surface-normal velocity is positive upwards.
The corresponding surface response can be calculated using Equation (27) and a discrete Fourier-transform routine.

Surface and basal velocities are compared in Figure 4 for such a basal front. The abrupt change in $u$ at the basal front is spread out over about $5 \mathrm{H}$ at the surface. Also, the trend of $u$ at the surface is not as smooth as would be expected. Instead, there is a flat of width about $1 H$ in the surface velocity over the basal discontinuity. The flat in the surface-parallel component of the surface velocity occurs because of reverse contributions when the high wavenumber Fourier components of $u_{\mathrm{b}}$ are filtered to the surface through the transfer function. These high wave-number components dominate near the basal front, and their reverse surface contributions break the larger-scale trend established by the lower wave-number contributions.

\subsection{Surface response for ramp at base}

An anomaly in the surface-parallel component of basal velocity that has the form of a ramp can be written as

$$
u_{\mathrm{b}}(x)= \begin{cases}U_{\mathrm{b}} & x<-r, \\ \frac{-U_{\mathrm{b}}}{r} x & -r \leqslant x \leqslant r, \\ -U_{\mathrm{b}} & x>r,\end{cases}
$$

$$
v_{\mathrm{b}}(x)=0 \text {. }
$$

The slope of the ramp is $-U_{\mathrm{b}} / r$, where $2 r$ is the horizontal distance taken up by the ramp.

Basal and surface velocities for $r=0.25 \mathrm{H}$ are shown in Figure 4. This produces a ramp in $u_{\mathrm{b}}$ of width $0.5 \mathrm{H}$. At the plotting scale, the calculated surface-velocity componencs are almost indistinguishable from those for a sharp basal front.

If the basal velocity ramp width is increased, the flat in $u_{\mathrm{s}}$ becomes less prominent, and the maximum amplitude of $v_{\mathrm{S}}$ decreases (see Fig. 4). However, the width of the basal ramp does not noticeably affect the width of the zone of the surface-velocity anomaly, as long as the basal ramp is less than about $5 H$ wide.

\subsection{Surface solution for Gaussian peak at base}

A pulse in basal velocity is plausible for both the surface-normal and surface-parallel components. An anomaly in the surface-parallel component at the bed which has the spatial form of a Gaussian peak is expressed as

$$
u_{\mathrm{b}}(x)=U_{\mathrm{b}} \frac{1}{\sqrt{2 \pi \sigma}} \exp \left[-\frac{1}{2}\left(\frac{x}{\sigma}\right)^{2}\right]
$$

where $\sigma$ is the standard deviation. The surface effects vary depending on the ratio of the standard deviation of the peak to the thickness of the ice $(\sigma / H)$. Three results are shown: a wide peak (Fig. 5a), a medium width peak (Fig. 5 b), and a narrow peak (Fig. 5c). As the peak is made narrower, $u_{\mathrm{s}}$ develops a dip over the center of the basal peak, and $v_{\mathrm{S}}$ becomes more pronounced. These effects are summarized in Figure 6 . The high wave-number terms of the basal velocity are the source of these variations (as was explained in section 4.1).

If a Gaussian pulse is made narrower and taller while holding the area constant in the limit of zero width, it approaches a delta function. The delta-function solution can also be found by differentiation of the solution for a basal front. From this point of view, the dip in surface velocity directly above a basal delta-function spike corresponds to the surface-velocity "flat" above a discontinuous front. The delta-function solution is qualitatively the same as Figure $5 \mathrm{c}$ for the narrow Gaussian pulse.

The solution for a delta-function anomaly in $u_{\mathrm{b}}$ provides the formal means for expressing the solution for any arbitrary spatial distribution of $u_{\mathrm{b}}$ in terms of a spatial decomposition based on a Green's function. (A similar 


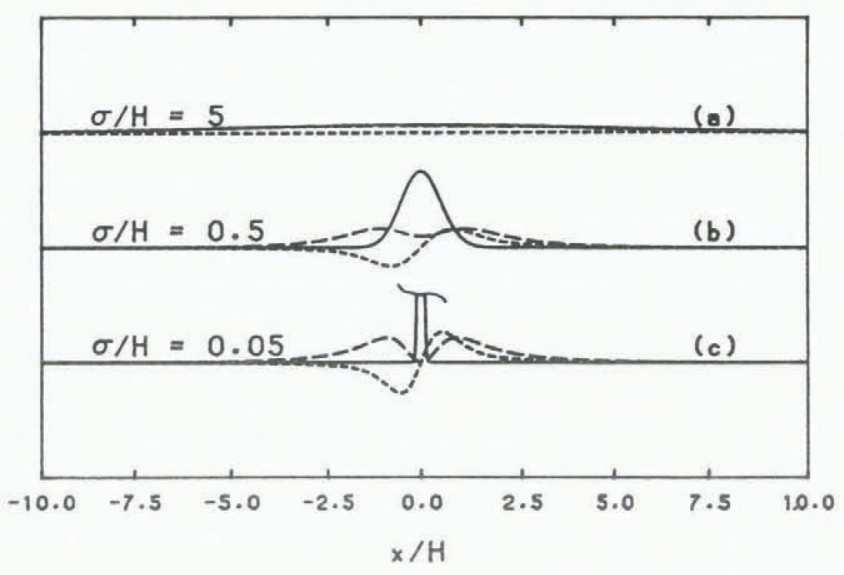

Fig. 5. Relative basal and surface velocities for Gaussian pulse basal velocity anomalies $u_{b}$, with (a) $\sigma / H=5$, (b) $\sigma / H=0.5$, and $(c) \sigma / H=0.05$. Solid line, $u_{b}$; dashed line, $u_{s}$ (where distinguishable from $u_{b}$ ); short dashed line, $v_{s}$ (positive upward). Basal velocity anomalies integrated over distance equal in all three cases.

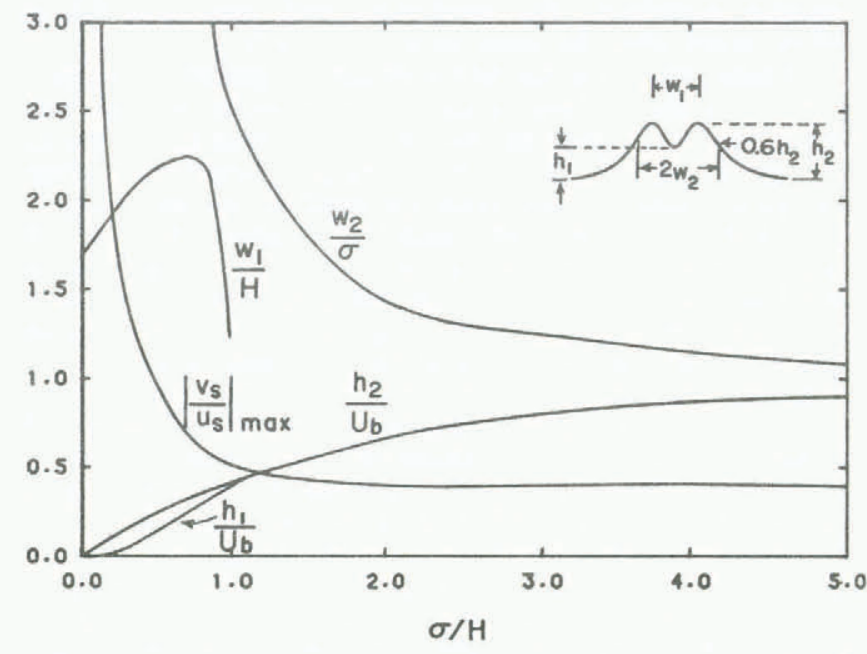

Fig. 6. Charcteristics of $u_{s}$ in response to Gaussian pulse basal velocity anomalies $u_{b}$, and their dependence on the longitudinal scale of the pulse.

solution is possible for a delta-function anomaly in $v_{\mathrm{b}}$.) Let the surface velocity at position $x$ caused by a unit basal delta function at $x^{\prime}$ be expressed as $G_{s}\left(x, x^{\prime}\right)=G_{s}\left(x-x^{\prime}\right)$. Figure 5c approximates $G_{s}\left(x-x^{\prime}\right)$ with $x^{\prime}=0$. By superposition, the surface solution for an arbitrary spatial distribution of $u_{\mathrm{b}}(x, t)$ is

$$
u_{\mathrm{s}}(x, t)=\int_{-\infty}^{\infty} u_{\mathrm{b}}\left(x^{\prime}, t\right) G_{\mathrm{s}}\left(x-x^{\prime}\right) \mathrm{d} x .
$$

Since the analytical representation of $G_{s}\left(x-x^{\prime}\right)$ derived above is very complex, this approach does not seem generally useful now. If a simple analytical approximation were fitted to $G_{s}\left(x-x^{\prime}\right)$, then Equation (31) could be very useful, but this is not pursued here.

One property of $G_{s}\left(x-x^{\prime}\right)$ can be used to arrive simply at a useful result. This property is

$$
\int_{-\infty}^{\infty} G_{s}\left(x-x^{\prime}\right) \mathrm{d} x=1 .
$$

This can be seen in several ways. For example, the solution for a basal delta function is the $x$ derivative of the solution for a unit basal front at $x^{\prime}$. Thus $G_{s}\left(x-x^{\prime}\right)$ for fixed $x^{\prime}$ gives the $x$ derivative of surface velocity for a unit basal front at $x^{\prime}$ and, when it is integrated over adequate distance from one side of the front to the other, it gives the total velocity jump at the surface and at the bed (Fig. 4). From Equations (31) and (32)

$$
\int_{-\infty}^{\infty} u_{\mathrm{s}}(x, t) \mathrm{d} x=\int_{-\infty}^{\infty} \int_{-\infty}^{\infty} u_{\mathrm{b}}\left(x^{\prime} t\right) G_{s}\left(x-x^{\prime}\right) \mathrm{d} x^{\prime} \mathrm{d} x=\int_{-\infty}^{\infty} u_{\mathrm{b}}\left(x^{\prime}, t\right) \mathrm{d} \mathrm{x}^{\prime},
$$

which shows the integrated velocity is the same at the surface and bed for any basal velocity anomaly.

A Gaussian pulse in the surface-normal component of basal velocity (perhaps caused by cavitation) can be represented as

$$
v_{\mathrm{b}}(x)=V_{\mathrm{b}} \frac{1}{\sqrt{2 \pi \sigma}} \exp \left[-\frac{1}{2}\left(\frac{x}{\sigma}\right)^{2}\right)
$$

Surface effects are shown for a wide peak (Fig. 7a), a medium-width peak (Fig. 7b), and a narrow peak (Fig. 7c). The cross-component effects are the same as for the

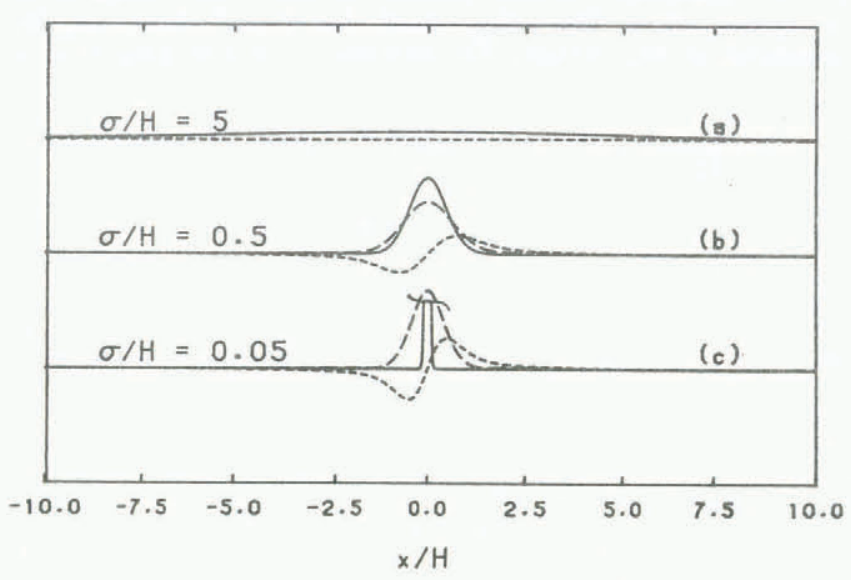

Fig. 7. Relative basal and surface velocities for Gaussian pulse basal velocity anomalies $v_{b}$, with (a) $\sigma / H=5$, (b) $\sigma / H=0.5$, and (c) $\sigma / H=0.05$. Solid line, $v_{b}$ (positive upward); dashed line, $v_{s}$ (positive upward); short dashed line, $u_{s}$. Basal velocity anomalies integrated over distance equal in all three cases.

surface-parallel basal anomalies (since $T_{v u s}=T_{u v s}$ ). The surface-normal component at the surface is reduced in amplitude and increased in longitudinal extent relative to the basal pulse, as the basal pulse is made narrower.

\section{DISCUSSION}

\subsection{Longitudinal scales of transfer}

Based on the considerations of the foregoing sections, four longitudinal scales of differing behavior may be identified. Basal velocity anomalies of a long scale appear at the surface unattenuated, and deformation-induced crosscomponent motions are negligible. At an intermediate scale, the surface-parallel and surface-normal velocity components have nearly the same spatial pattern at the surface as at the bed, but with reduced amplitudes. At this scale, crosscomponent motions caused by ice deformation become noticeable. At a short scale, while the surface-normal component at the surface is reduced in amplitude from that of the basal surface-normal component, the surface-parallel component at the surface is significantly altered in both amplitude and spatial pattern in comparison to that at the bed. At this short scale, cross-component motions are substantial. Finally, there is a very short scale at which there is essentially no response at the surface.

These systematics are best seen with reference to harmonic basal anomalies (Fig. 3) and basal peaks (Figs 5, 
6 , and 7). The boundary between the four scales can be roughly identified as $10 H$ (long to intermediate), $5 H$ (intermediate to short), and $1 H$ (short to very short). Since the change in behavior with longitudinal scale is gradational, these boundaries cannot be positioned precisely. Furthermore, the positions of the boundaries depend to some extent on the spatial pattern as can be seen from comparison of Figures 3 and 6 . Any real pattern of basal velocity variation will likely have features at a variety of scales. A basal velocity front is one example for which there are effects at all of these scales (Fig. 4).

5.2. Deformation-induced surface-normal motions and estimates from surface strain-rate

For intermediate and short scales, Figures 3 and 6 show that a basal velocity anomaly such that $u_{\mathrm{b}} \neq 0$ and $v_{\mathrm{b}}=0$ causes both $u_{\mathrm{s}}$ and $v_{\mathrm{s}}$ to be non-zero, and $v_{\mathrm{s}}$ may be larger than $u_{\mathrm{s}}$. From ice continuity (Equation (1)), and assuming $v_{\mathrm{b}}=0, v_{\mathrm{s}}$ is

$v(x, o, t)=\int_{H}^{o} \frac{\partial v}{\partial y}(x, y, t) \mathrm{d} y=\int_{0}^{H} \frac{\partial u}{\partial x}(x, y, t) \mathrm{dy}=H\left\langle\frac{\partial u}{\partial x}\right\rangle / H$.

If the anomalous surface-parallel motion were independent of depth, then $\langle\partial u / \partial x\rangle_{H}$ could be found from $\partial u_{\mathrm{s}} / \partial x$ measured at the surface. The problem is that in general $u$ is
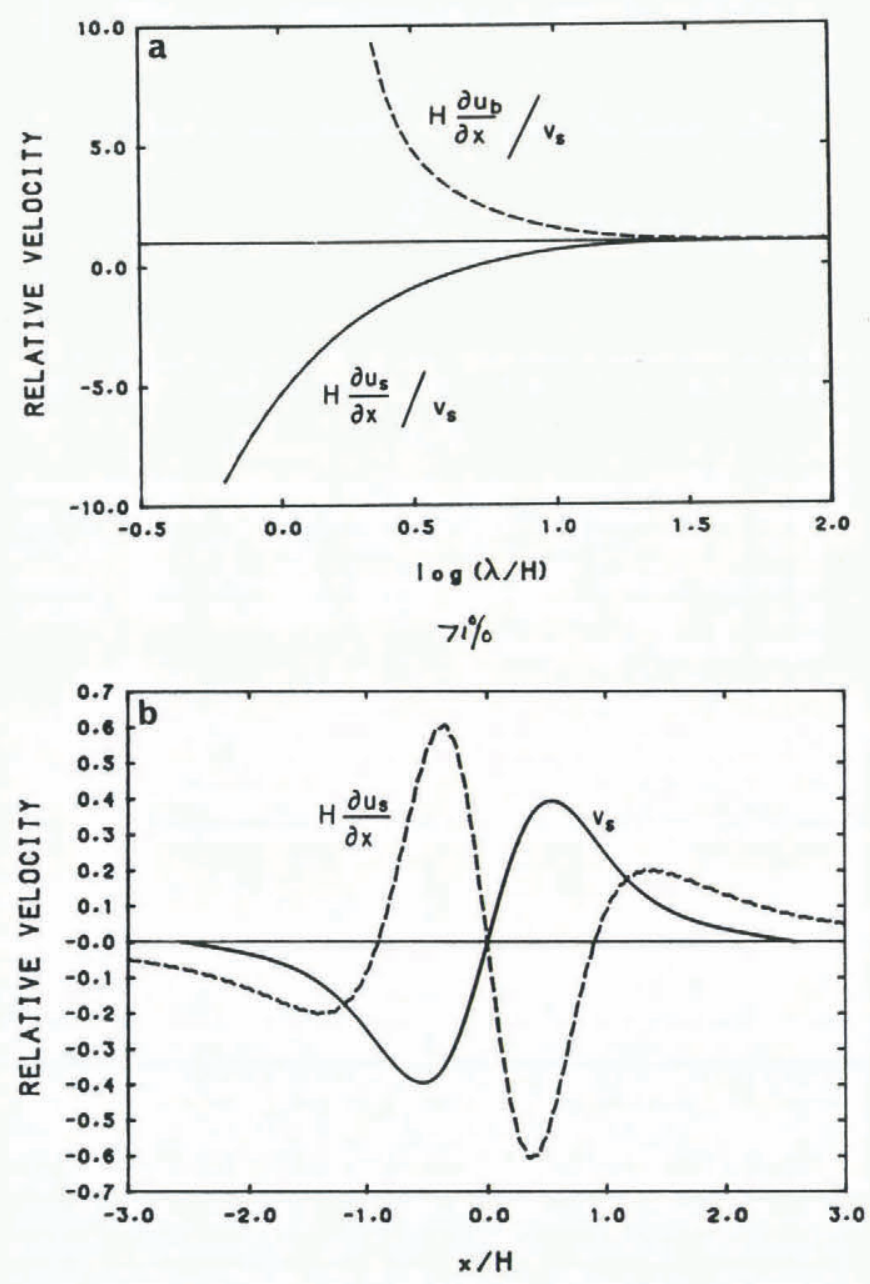

Fig. 8. (a) Surface-normal velocity calculated as $H \partial u / \partial x$ scaled by $v_{s}$ from mathematical model for harmonic basal velocity anomaly $u_{b}$. Solid line, $\left(H \partial u_{s} / \partial x\right) / v_{s} ;$ dashed line, $\left(H \partial u_{b} / \partial x\right) / v_{s}$.

(b) Surface-normal velocity (positive upward) calculated as $H \partial u_{s} / \partial x$ (dashed line) compared with $v_{s}$ from mathematical model (solid line), for a Gaussian pulse basal velocity anomaly $u_{b}$ with $\sigma / H=0.05$, of maximum amplitude $u_{b}(0)=10$. attenuated toward the surface and $\partial u_{\mathrm{S}} / \partial x$ will underestimate the magnitude of the average of $\partial u / \partial x$ over depth. Furthermore, at the short scale the signs can be opposite. These problems are illustrated in Figure 8.

\subsection{Problems of interpretation of measured surface-velocity} and uplift variations

On Variegated Glacier, propagating "mini-surges" occurred quasi-periodically during the early melt seasons for several years prior to the main surge. These were characterized by a zone of accelerated motion which propagated down-glacier at about $0.1-0.6 \mathrm{~km} \mathrm{~h}^{-1}$. At a given location, speed rose rapidly over a few hours to a sharp peak, dropped rapidly and then more slowly over about $1 \mathrm{~d}$ as the zone approached (paper in preparation by B. Kamb and H.F. Engelhardt). Often there was a secondary velocity peak following the first principal one by several hours (Raymond and Malone, in press.)

The surface-parallel velocity anomalies $u_{\mathrm{s}}$ averaged over $1 \mathrm{~d}$ were on the order of $0.5-1 \mathrm{~m} \mathrm{~d}^{-1}$ and resulted in extra anomalous surface displacements of $0.5-1 \mathrm{~m}$ over the $1 \mathrm{~d}$ interval of a mini-surge. The peaks in $u_{\mathrm{s}}$ were on the order of three to four times larger than the day-averaged values. In addition there was a noticeable anomaly $v_{\mathrm{s}}$, which produced a relatively rapid uplift rate of up to about $1 \mathrm{~m}$ $\mathrm{d}^{-1}$ over one to several hours, followed by a slower more extended subsidence. The maximum uplift was about $0.1 \mathrm{~m}$ and occurred after the peak in $u_{\mathrm{s}}$ by 1 or $2 \mathrm{~h}$.

These time intervals and propagation speeds correspond to spatial scale of from about $1 \mathrm{~km}$ to more than $10 \mathrm{~km}$ which can be compared to the ice thickness of about $0.4 \mathrm{~km}$. Therefore, the surface-velocity patterns of these mini-surges have features from the small to the large scale.

Figure 9 shows an example constructed from a superposition of ramps and a Gaussian spike for $u_{\mathrm{b}}$, and a Gaussian pulse for $v_{\mathrm{b}}$. Surface velocities are shown both with and without the effects from $v_{\mathrm{b}}$. This example shows some of the qualitative features of mini-surge-velocity variation. Due to the simplifications of the model, it is premature to attempt a detailed inversion of measured surface velocity for calculation of basal velocity Furthermore, this will in any case not be straightforward, due to the high attenuation between the bed and surface for short wavelengths and an intermediate wavelength interval (about $5 H$ for this model), which causes problems of resolution and accuracy. Nevertheless, some semiquantitative conclusions are possible. The broad-scale asymmetric peak in mini-surge velocity is of long enough

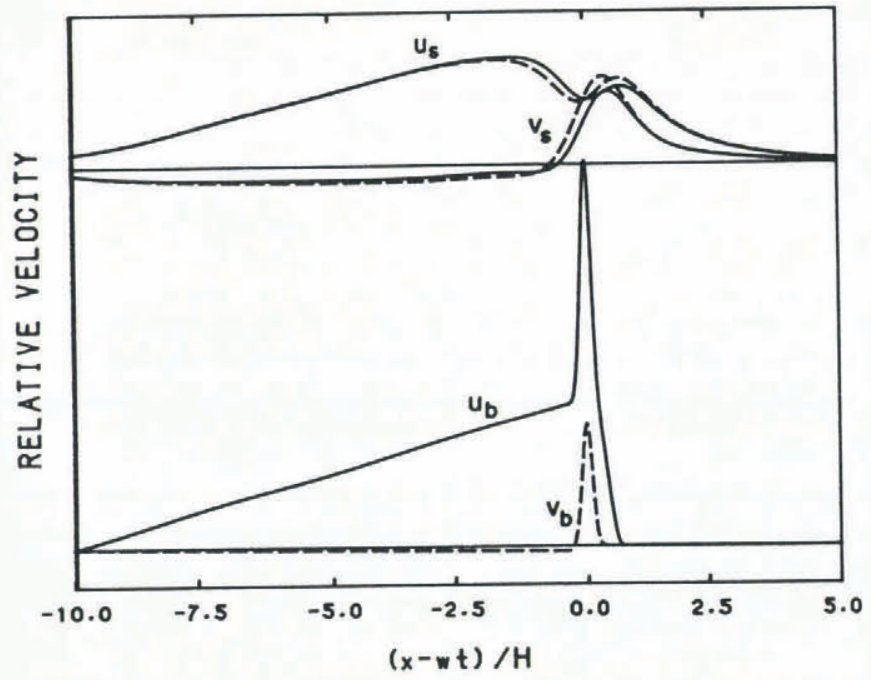

Fig. 9. Surface velocity components $u_{s}$ and $v_{s}$ (upper two solid curves) for a hypothetical basal velocity anomaly with component $u_{b}$ (lower solid curve). Addition of basal component $v_{b}$ (lower dashed curve) results in total surface components $u_{s}$ and $v_{s}$ (shown by upper two dashed curves). Anomalies propagating with speed w; surface-normal velocity is positive upward. 
scale that it probably resembles in shape and amplitude the actual variation at a similar scale at the bed, except for some broadening of the velocity rise at the surface in comparison to the bed. The narrow principal peak and the subsequent secondary peak may be indicative of a single sharp peak at the bed of substantially higher velocity and represent intermediate- to short-scale features. The principal peak at the surface has a half-width of about one depth, which suggests the peak at the bed could be narrower and have a velocity anomaly more than three times that at the surface. Furthermore, the positions of the peak at the bed may be shifted relative to the principal peak at the surface, probably toward the secondary peak. Finally, at this scale the deformation-induced surface-normal velocity conponent at the surface will have an amplitude similar to the anomalous surface-parallel component at the surface. Uplift determined by integration of $v_{\mathrm{s}}$ when $v_{\mathrm{b}}=0$ shows a rapid rise and a subsequent slower fall. The maximum uplift is $\approx 0.13$ times the anomalous surface-parallel displacement caused by the passage of the velocity wave; this is seen by comparison of the areas under the positive parts of the $v_{\mathrm{S}}$ and the $u_{\mathrm{s}}$ curves. This shows that a large fraction or possibly all of the surface uplift during mini-surges could be explained by internal deformation without uplift at the bed.

Iken and others (1983) have observed variations in surface velocity and elevation on Unteraargletscher at an approximately $4 \mathrm{~d}$ time resolution. At this time resolution, they find a correlated velocity increase and uplift of the surface during an approximately 7 month summer season. Several short-term velocity and uplift events lasting more than $4 \mathrm{~d}$ are superimposed on it. These short-term velocity variations have some resemblances to the mini-surges of Variegated Glacier; however, little is known about their spatial variation or propagation. Assuming the Unteraargletscher events propagate at speeds similar to or faster than the Variegated Glacier mini-surges, which is consistent with the description of available information, the durations of the features would indicate that these events have large spatial scale and are free from the complexities of the short and intermediate scales in the foregoing analyses. Iken and others (1983) have carefully considered in detail various possible contributions to the surface uplift and conclude that its major features must arise from the opening of cavities at the bed but, based on limited measurements of surface strain-rate changes, they caution that vertical ice straining could be a major contribution. We emphasize here the possible major errors when using surface values of longitudinal strain-rate to estimate averages over depth unless the spatial scale of velocity variation is wel known. Furthermore, unlike a velocity measurement, which represents an average over time, an uplift measurement is a sample at a single time and may not be representative of the time interval over which the velocity has been averaged.

\subsection{Limitations of the model}

A major limitation of the model is the assumption of a linear viscous fluid rheology to represent ice behavior. Some of the features of the strain-rate pattern during Variegated Glacier mini-surges show dramatic changes on time-scales short compared to the time needed to establish steady-state creep in experiments. This indicates possible visco-elastic effects. This problem has been examined using a linear visco-elastic Maxwell rheology, which gives some difference in behavior in comparison to the purely viscous rheology, but these differences are not major (paper in preparation by M.J. Balise). More importantly, ice creep is better approximated by a power law with power of 3-4 than by a linear fluid (power of 1). This could lead to some substantial differences in behavior. In the limit in which the velocity anomalies induced at the bed and their strain-rate contributions are much smaller than the steady-state velocity and strain-rate, the velocity-anomaly field will occur in a distribution of effective viscosity controlled by the straining associated with the steady-state motions. In this circumstance, a perturbation solution could be attempted (Hutter, [ $\left.\left.{ }^{c} 1983\right]\right)$. The effective viscosity will then tend to be low near the bed and high near the surface (Whillans and Johnson, 1983). This will tend to promote recirculation of the velocity anomaly near the bed and probably increase the length for transition between the short and intermediate scales described above. If the velocity anomalies and corresponding strain-rates are large in comparison with the steady motion, the anomalies themselves will significantly alter both the vertical and longitudinal structure of the effective viscosity field with possible major effects on the transfer of amplitude and pattern between the surface and bed. In both of these limits we expect equally or more complex behavior than for the linear fluid rheology and no easing of the difficulties of interpreting surface variations in terms of those at the bed.

If basal velocity variations do not extend over widths significantly larger than the depth, one may expect that their transmission to the surface may be different from that calculated here. Three-dimensional flow calculations would be needed to account for this.

Finally, these calculations do not address the question of what sliding-velocity variations are physically possible. Some of the mathematically illustrative solutions derived represent idealizations that likely could not exist in reality (for example, a sharp basal velocity front). Nevertheless, in the absence of a compelling sliding law, an appropriate step is to attempt measurement of basal velocity from the surface. From that point of view, this paper begins to show what is possible and what is not.

\section{ACKNOWLEDGEMENTS}

This work was supported by the U.S. National Science Foundation under grants DPP-8200725 and DPP-8408317. T. Jóhannesson and $\mathrm{E}$. Waddington provided many valuable comments during preparation of the manuscript.

\section{REFERENCES}

Bindschadler, R. 1983. The importance of pressurized subglacial water in separation and sliding at the glacier bed. Journal of Glaciology, Vol. 29, No. 101, p. 3-19.

Engelhardt, H.F., and others. 1978. Basal sliding and conditions at the glacier bed as revealed by bore-hole photography, by H.F. Engelhardt, W.D. Harrison, and B. Kamb. Journal of Glaciology, Vol. 20, No. 84, p. 469-508.

Haefeli, R. 1970. Changes in the behaviour of the Unteraargletscher in the last 125 years. Journal of Glaciology, Vol. 9, No. 56, p. 195-212.

Harrison, W.D., and others. In press. Short period motion events on Variegated Glacier as observed by automatic photography and seismic methods, by W.D. Harrison, C.F. Raymond, and P. MacKeith. Annals of Glaciology, Vol. 8.

Hodge, S.M. 1974. Variations in the sliding of a temperate glacier. Journal of Glaciology, Vol. 13, No. 69, p. 349-69.

Hutter, K. [ $\left.{ }^{c} 1983.\right]$ Theoretical glaciology; material science of ice and the mechanics of glaciers and ice sheets. Dordrecht, D. Reidel Publishing Company/Tokyo, Terra Scientific Publishing Company.

Hutter, K., and others. 1981. First-order stresses and deformations in glaciers and ice sheets, by $\mathbf{K}$. Hutter, F. Legerer, and U. Spring. Journal of Glaciology, Vol. 27, No. 96 , p. $227-70$.

Iken, A. 1978. Variations of surface velocities of some Alpine glaciers measured at intervals of a few hours. Comparison with Arctic glaciers. Zeitschrift für Gletscherkunde und Glazialgeologie, Bd. 13, Ht. 1/2, 1977, p. 23-25.

Iken, A., and others. 1983. The uplift of Unteraargletscher at the beginning of the melt season - a consequence of water storage at the bed? By A. Iken, H. Röthlisberger, A. Flotron, and W. Haeberli. Journal of Glaciology, Vol. 29, No. 101 , p. 28-47.

Kamb, B., and Echelmeyer, K.A. In press. Stress-gradient coupling in glacier flow: I. Longitudinal averaging of the influence of ice thickness and surface slope. Journal of Glaciology. 
Langdon, J., and Raymond, C.F. 1978. Numerical calculation of adjustment of a glacier surface to perturbations of ice thickness. Materialy Glyatsiologicheskikh Issledovaniy. Khronika. Obsuzhdeniya, Vyp. 32, p. 233-39.

Nye, J.F. 1952. The mechanics of glacier flow. Journal of Glaciology, Vol. 2, No. 12, p. 82-93.

Raymond, C.F., and Malone, S. In press. Propagating strain anomalies on Variegated Glacier, Alaska, U.S.A. Journal of Glaciology.
Vivian, R. 1980. The nature of the ice-rock interface: the results of investigation on $20000 \mathrm{~m}^{2}$ of the rock bed of temperate glaciers. Journal of Glaciology, Vol. 25, No. 92, p. 267-77.

Whillans, I.M., and Johnsen, S.J. 1983. Longitudinal variations in glacial flow: theory and test using data from the Byrd Station strain network, Antarctica. Journal of Glaciology, Vol. 29, No. 101, p. 78-97.

MS. received 4 April 1985 and in revised form 16 August 1985 